\title{
Successful Surgical Treatment of Arnold-Chiari Malformation Combined with a Pontocerebellar Cyst and Unilateral Hearing Loss
}

\author{
Shamil Safin ${ }^{1,2}$, Ilmira Gilemkhanova ${ }^{1,3}$, Khristina Derevyanko ${ }^{1,4}$, S Muruga Subramaniam ${ }^{1,5,6 *}$ and Ilnur Nizamiev $^{1}$ \\ ${ }^{1}$ Department of Neurosurgery and medical rehabilitation with an ICPE (Institute of Continuing Professional Education) course, Bashkir \\ State Medical University, Russia
}

${ }^{2}$ Department of Neurosurgery, GG Kuvatov Republican Clinical Hospital, Russia

${ }^{3}$ Department of Neurosurgery, Republican Children's Clinical Hospital, Russia

${ }^{4}$ Department of Neurology, Clinic of Bashkir State Medical University, Russia

${ }^{5}$ Departments of Surgery, Division of Neurotrauma, Malaysia

${ }^{6}$ Melaka Manipal Medical College, Manipal University, Malaysia

*Corresponding author: S Muruga Subramaniam, Department of Neurosurgery and medical rehabilitation with an ICPE (Institute of Continuing Professional Education) course, Bashkir State Medical University, UFA, Russia

\begin{abstract}
Background:Cochleardysfunction, is considered one of the difficulttopical and importantareas in modern otorhinolaryngological practice. Diagnosis and treatment of cochlear dysfunction is even more complicated in combined pathologies. There have been reported only few cases of a combined with Arnold-Chiari malformation with hearing impairment.

Case description: 34 years old male, was admitted in Republican Clinical Hospital G.G. Kuvatov under neurosurgical care. Patients main complaints was hearing loss associated with "tinnitus" on the left sided, morning headaches, dizziness, and unstable gait. The patient noted a gradual loss of hearing on his left ear over the years. He was diagnosed to have Arnold chiari malformation type 1 with combined hearing loss.

Conclusion: Good planned surgical strategies and operative techniques the hearing loss was restored, and his neurological symptoms was relieved.
\end{abstract}

Keywords: Arnold-Chiari malformation; Pontocerebellar cyst; Hearing impairment

Abbreviations and Acronyms: ACM: Arnold Chiari Malformation; MRI: Magnetic Resonance Imaging

\section{Introduction}

Arnold Chiari malformation (ACM) is a group of congenital malformations of the hindbrain development that affect structural relationships of the cerebellum, brain stem, supracervical spinal cord and base of skull [1]. Diagnosing ACM is usually with certain difficulties, since not all cases of cerebellar tonsils descent below the great occipital foramen with clinical manifestations. The clinical signs of ACM themselves are very polymorphic. M.A. Valiulin (1996), reported that the initial manifestations of type I ACM usually with cervical-occipital and facial pains, hearing impairments, dizziness, balance disorders, ataxia, facial hypesthesia, dysphagia, dysphonia, diplopia, nystagmus, arm pains and weakness in the limbs. In patients with type I ACM combined with myelosyringosis, the first symptoms of the disease appear later stage [2]. 
Some journals reported cases of hearing impairment in patients with type I ACM in its onset [3,4]. K.S. Paul et al. (1983) reported tinnitus in $9.9 \%$ of patients among 71 patients with type I ACM examined [5]. Studies done by R.E. Rydell, J.L. Pulec (1971) with 130 patients with Arnold Chiari type I, discovered bilateral progressive hearing impairment in $22.3 \%$ of patients [6]. We are reporting a clinical case of Arnold-Chiari malformation complicated by a pontocerebellar cyst and left-sided hearing loss.

\section{Case Description}

34 years old, male was admitted for treatment at Republican Clinical Hospital G.G. Kuvatov with chief complaint of hearing loss, "tinnitus" on the left sided, morning headache, dizziness, and unstable gait. The patient noted a gradual loss of hearing in the left ear over the years. No family history with similar illness. Neurological examination noted convergent nystagmus, moderate truncal ataxia, clinically with a combination of cerebellar ataxia.

Neuropsychological examination no cognitive impairment. Patient underwent an audiometric test and noted a reduction on the left ear with $65 \mathrm{~dB}$, and right side with normal readings. We came up to a diagnosis of stage 4 left sided hearing loss with bordering deafness.

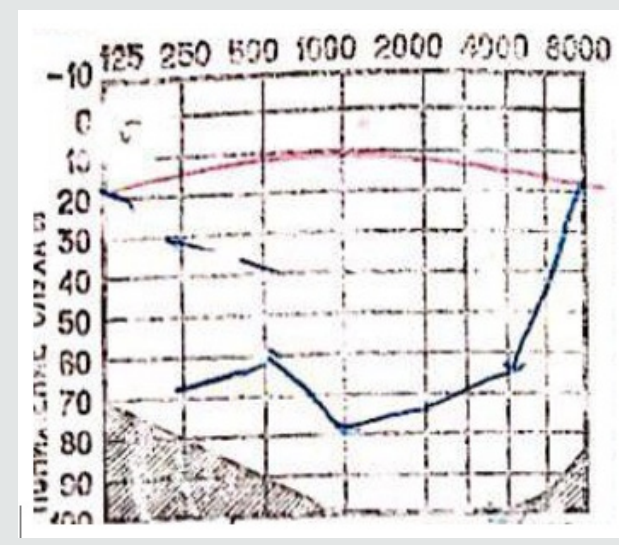

Figure 1.

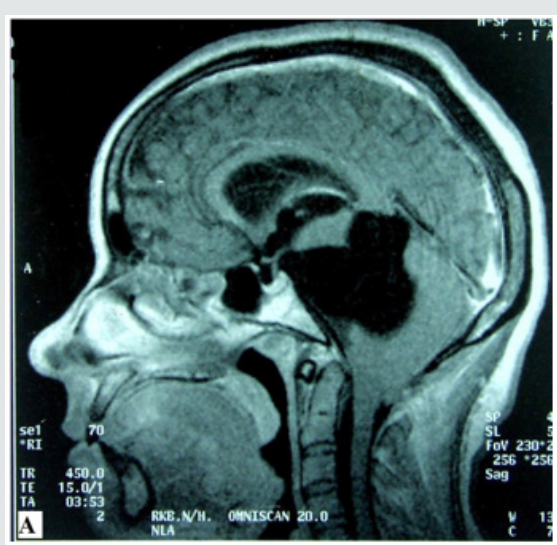

Figure 2: Cyst at the left cerebellopontine angle.
Magnetic resonance imaging (MRI) of the brain noted arnold chiari malformation (ACM) with $10 \mathrm{~mm}$ descent of cerebellum tonsils, with a dorsal compression at the level of the cervicalmedullary junction, and a cyst at the left cerebellopontine angle (Figure 1,2).

Diagnosis of Arnold-Chiari malformation with left-sided pontocerebellar cyst was made. After a careful evaluation and discussion with patient, surgical option of treatment was planned after discussing with patient. Surgical option mainly to relieve the nerve compression especially the $8^{\text {th }}$ nerve by pontocerebellar cyst. The patient underwent resection of cerebellum tonsils, with an opening of cistern connecting the pontocerebellar cerebrospinal fluid cavity and airtight fascioduraplasty.

Postoperative MRI of the brain reveals regression of the left cerebellopontine angle cyst (Figure 3,4). Dorsal compression is relieved at the level of the cervical-medullary junction. During the recovery period patient feels improvement in his left ear. Audiometric test noted to have $30 \mathrm{~dB}$, and diagnosis of stage 1 leftsided hearing loss.

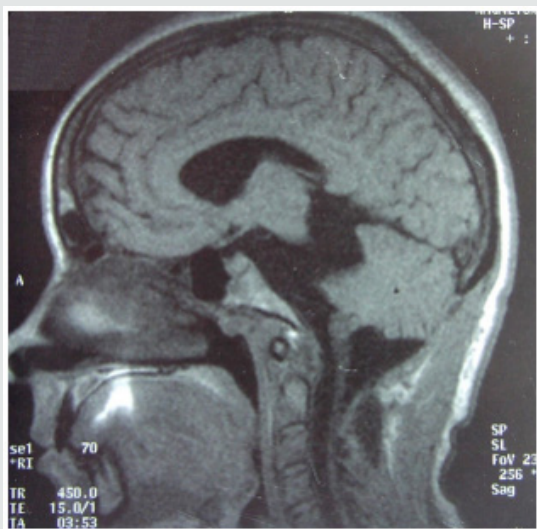

Figure 3: Regression of the left cerebellopontine angle cyst.

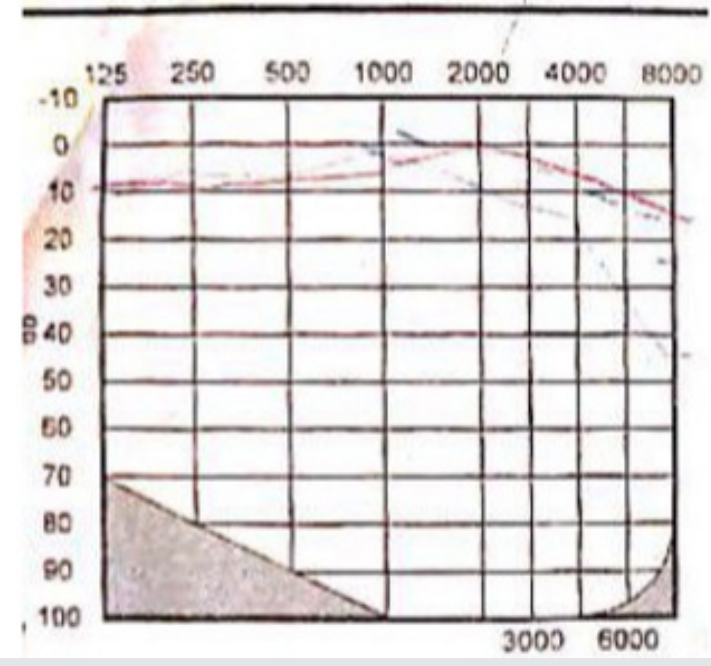

Figure 4. 


\section{Discussion}

The major discussion of ACM and intervention remain debatable. In 1999 Milhorat TH et al. published data on prospective analysis of 346 patients with Arnold-Chiari malformation of which $36 \%$ suffered from hearing loss.

They identified 4 possible mechanisms of damage of the eighth pair of cranial nerves:

a) Nerve fibers tension as a result of brain stem descent.

b) Nuclei compression of the eighth pair of cranial nerves by cerebellum tonsils.

c) Ischemic damage to the nuclei due to compression of the cerebellar artery.

d) Cochlear damage, transmission of increased pressure of cerebrospinal fluid through the abnormal cochlea.

The data of other local and international authors are reduced to the fact that hearing impairment is associated with stretching of auditory nerves and compression of the brain stem in the region of the great occipital foramen [7,8]. G. Bertrand (1973) proposed a hypothesis of ischemic damage to the cochlear nuclei of the brain stem when the posterior inferior cerebellar artery is damaged and moves down along with the cerebellum tonsils and is subject to compression at the level of the great occipital foramen [9].

Good recovery of hearing after the surgical treatment to relieve the compression of the nerve fibers by the pontocerebellar cyst resulting from cerebrospinal fluid disturbances associated with the Arnold-Chiari malformation (Figure 5).

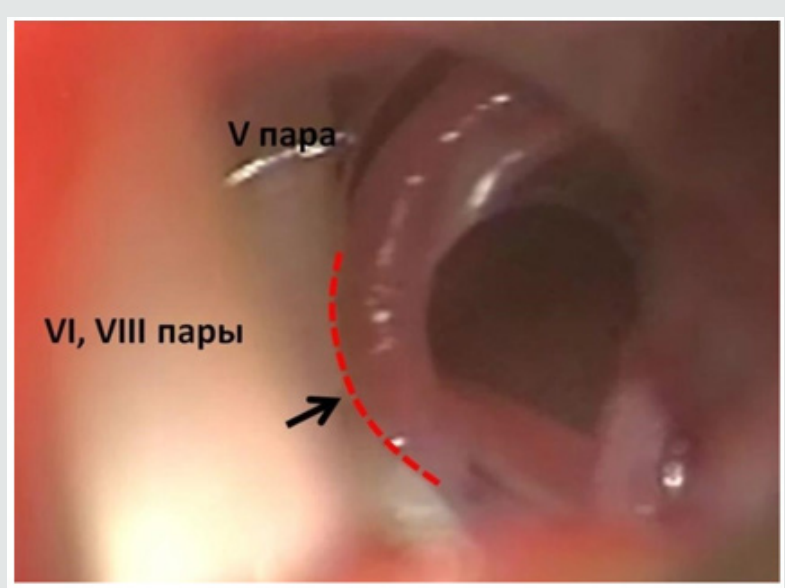

Figure 5: Nerve.

\section{Abbreviations and Acronyms:}
a. ACM - Arnold Chiari malformation
b. MRI - Magnetic Resonance Imaging

\section{Conclusion}

A good selection of patients and studying the comorbid, progression of the disease requires an additional diagnostics tool. After a clinical examination and neuroimaging, a diagnosis of ACM and a pontocerebellar cyst combined with unilateral hearing loss was established. After successful surgical treatment, the patient's hearing was restored, which is confirmed by audiometric data. Thus, an assessment of the otolaryngological status makes clearer the possible objective of malfunctions of the peripheral and central parts of the sensory systems of the brain, mainly located in the area of interest of the pathological process, which is important when deciding on the tactics of surgical treatment.

\section{References}

1. Bertrand G (1973) Dynamic factors in the evaluation of syringomyelia and syringobulbia. Clin Neurosurg 20: 322-333.

2. Kumar A, Patni A, Charbel F (2002) The Chiari I Malformation and the Neurotologist. Otol Neurotol 23(5): 727-735.

3. Milhorat TM, Nishikawa M, Kula RW, Yosef D Dlugacz (2010) Mechanisms of cerebellar tonsil herniation in patients with Chiari malformations as a guide to clinical management. Acta Neurochir (Wien) 152(7): 11171127.

4. Milhorat H, Chou W, Elizabeth M, Kotzen M, Marcy C Speer (1998) Chiaril Malformation: Description of Syndrome, Clinical Manifestation, and Inheritance Patterns in 364 Symptomatic Patients. Sep Neurosurgery; 43(3): 674-674.

5. Milhorat TM, Nishikawa M, Kula RW, Yosef D Dlugacz (2010) Mechanisms of cerebellar tonsil herniation in patients with Chiari malformations as a guide to clinical management. Acta Neurochir (Wien) 152(7): 11171127.

6. Paul KS, Lye RH, Strang FA, Dutton J (1983) Arnold-Chiari malformation. Review of 71 cases. J Neurosurg 58(2): 183-187.

7. Rydell RE, Pulec JL (1971) Arnold-Chiari Malformation: Neuro-otologic Symptoms. Arch Otolaryngol 94(1): 8-12.

8. Sperling NM, Franco RA, Milhorat TH (2001) Otologic Manifestations of Chiari I Malformation. Otology \& Neurotology 22 (5): 678-681.

9. Valiulin MA (1996) Syringomyelia and Chiari malformation: initial clinical manifestations and results of surgical treatment: Abstract. MA Valiulin-SPb PP: 23. 
CC (P) This work is licensed under Creative Commons Attribution 4.0 License

To Submit Your Article Click Here: Submit Article

DOI: $10.32474 /$ JJNBD.2020.04.000178

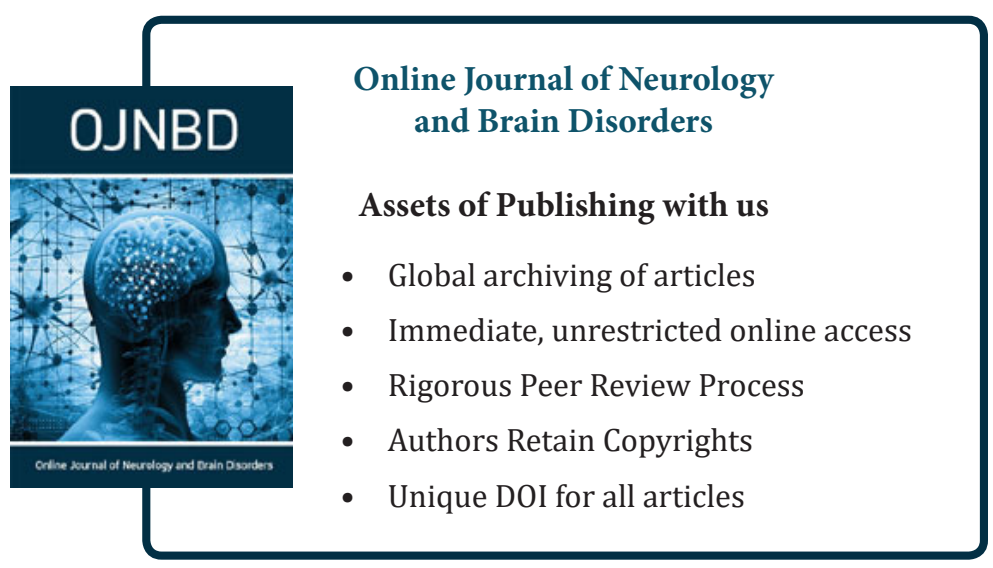

